\title{
전류밀도에 따른 플립칩 $\mathrm{Sn}-\mathrm{Ag}$ 솔더 범프의 Electromigration 손상기구 분석
}

\author{
김가희 $^{1} \cdot$ 손기락 $^{1} \cdot$ 박규태 $^{2} \cdot$ 박영배 $^{1, *}$ \\ ${ }^{1}$ 안동대학교 신소재공학부, 청정에너지소재기술연구센터 \\ ${ }^{2}$ 앰코테크놀로지 코리아
}

\section{Effect of Current Densities on the Electromigration Failure Mechanisms of Flip-Chip Sn-Ag Solder Bump}

\author{
Gahui Kim ${ }^{1}$, Kirak Son ${ }^{1}$, Gyu-Tae Park ${ }^{2}$, and Young-Bae Park ${ }^{1, *}$ \\ ${ }^{1}$ School of Materials Science and Engineering, Andong National University, Andong 36729, Republic of Korea \\ ${ }^{2}$ Amkor Technology Korea Inc, Gwangju 61006, Republic of Korea
}

\begin{abstract}
The effect of current densities on the electromigration (EM) failure mechanism of flip chip $\mathrm{Cu} / \mathrm{Ni} / \mathrm{Sn}-\mathrm{Ag} / \mathrm{Cu}$ solder bumps was investigated under stressing conditions at current densities ranging from 5.0 6.9 $\times 10^{3} \mathrm{~A} / \mathrm{cm}^{2}$ at $150{ }^{\circ} \mathrm{C}$. The EM failure times at $5.0 \times 10^{3} \mathrm{~A} / \mathrm{cm}^{2}$ were around 11 times longer than at $6.9 \times 10^{3} \mathrm{~A} / \mathrm{cm}^{2}$. A systematic failure analysis considering stressing time showed that a current density of $5.0 \times 10^{3} \mathrm{~A} / \mathrm{cm}^{2}$ induced pancake void propagation near the $\mathrm{Cu}_{6} \mathrm{Sn}_{5}$ intermetallic compound/solder interface at the cathode, while a current density of $6.9 \times 10^{3} \mathrm{~A} / \mathrm{cm}^{2}$ produced severe Joule heating due to high current crowding near the solder/ $\mathrm{Cu}_{6} \mathrm{Sn}_{5}$ interface. This was due to electrons entering the location at the cathode, which led to local melting of the solder and fast $\mathrm{Cu}$ consumption. It was determined that the EM failure mechanisms of flip chip Sn-Ag solder strongly depend not only on the Ni barrier effect but also on current density, which drives the dominant failure mechanisms of pancake voiding and local Joule-heating melting.
\end{abstract}

(Received May 11, 2017; Accepted August 16, 2017)

Keywords: electrical/electron materials, soldering, diffusion, scanning electron microscopy(SEM), electromigration

\section{1. 서 론}

최근 급속한 IT산업 발전에 따라 전자 패키징 기술도 매우 빠르게 경박단소 방향으로 혁신적으로 발전되고 있으며, 많 은 데이터의 처리 기능을 구현하기 위해 하나의 패키지 내에 많은 칩을 통합시키는 새로운 전자 패키징 기술이 요구되고 있다 [1]. 이를 위해 반도체 1차 접속을 위해 플립칩 무연솔더 접합 기술이 널리 이용되고 있고, through silicon via 및 fan-out wafer-level package 등의 3차원 적층 패키징 기술들 이 최근 활발히 개발되고 있다 [2-7]. 가장 널리 사용중인 플 립칩 기술은 반도체 칩 입출력 단자 패드에 무연 솔더 도금을 이용한 범프를 형성하여 칩 표면이 기판으로 향하게 하여 칩

*Corresponding Author: Young-Bae Park

[Tel: +82-54-820-5121, E-mail: ybpark@anu.ac.kr]

Copyright (c) The Korean Institute of Metals and Materials
을 기판에 직접 실장하는 기술이다 $[1,8]$.

플립칩 접합기술은 칩 표면 전체에 균일하게 형성된 솔더 범프를 이용하여 기판과 직접 연결하여 접속부 길이가 최소 화 되기 때문에 전기적인 성능이 우수하다 [9]. 또한 칩 전체 의 면적을 입출력 단자로 활용이 가능하여 집적도가 매우 향 상되어 공간 및 전력 면에서 효율이 높아져 장치의 소형화 및 고집적화 추세에 맞출 수 있는 장점과 열 방출 역할을 하는 범프에 의해 냉각성능도 우수하다 [9].

플립칩 접합기술에 사용되는 솔더 범프 재료로서 오랫동 안 사용해온 $\mathrm{Sn}-\mathrm{Pb}$ 계 솔더는 가격이 저렴하고 우수한 솔더 링 특성을 가지고 있으나, 유해물질 제한지침 (Restriction of Hazardous Substances Directive, RoHS) 때문에 전자제품에 사용을 금지하고 있다 [10-12]. 이러한 이유로 $\mathrm{Ag}, \mathrm{Zn}, \mathrm{In}, \mathrm{Bi}$ 및 $\mathrm{Cu}$ 등을 함유한 다양한 $\mathrm{Sn}$ 계 합금이 사용되고 있는데, 도 
금공정을 통한 $\mathrm{Sn}-\mathrm{Ag}$ 계 솔더 합금을 가장 널리 사용 중이다 [13].

무연솔더를 플립칩 접합에 적용하기 위해 인쇄회로기판의 표면처리 방법도 여러 가지가 있다. 대표적인 표면처리 방법 으로는 유기 땜납성 보존제(organic solderability, OSP), 무전 해 $\mathrm{Ni}$ 도금/ $\mathrm{Au}$ 치환 도금(electroless nickel immersion gold, $\mathrm{ENIG)}$ 등이 적용되고 있다 [10,14-17]. 이 중 OSP는 alkyl imidazole 형태의 유기 화합물을 구리 위에 선택적으로 도포 가 되어 미세 회로에 적합한 처리 방식이나, 유기 물질로 도 포되어 있기 때문에 취급에 유의할 필요가 있다 [18]. 이러한 이유 외에도 $\mathrm{OSP}$ 처리 사용이 증가하는 이유는 제조공정이 쉽고 가격이 가장 싼 장점을 가지기 때문이다.

한편, 기술 발전에 따라 솔더 범프 크기가 점점 작아짐에 따라 솔더 범프에 흐르는 전류밀도는 점점 증가되고 있어서 electromigration(EM)손상이 무연 솔더 접합부의 심각한 전 기적 신뢰성 문제로 많이 보고되고 있다 [19-23]. 플립칩 솔 더 접합부의 솔더조성, under bump metallurgy(UBM) 및 기 판 표면처리 조건, 온도 및 전류 인가 조건 등에 따라 다양한 $\mathrm{EM}$ 손상기구가 보고되고 있다 [19-23]. 특히, 전자가 유입되 는 음극 부분에서 보이드가 형성되어 솔더와 금속간 화합물 계면을 따른 pancake-type 보이드 전파 손상기구[24]와 전자 가 유입되는 음극 부분에서 솔더 범프와 배선 사이에 국부적 인 전류집중 및 Joule heating에 의한 융해 손상기구[25]의 2 가지를 대표적인 무연 솔더 접합부의 $\mathrm{EM}$ 손상기구라고 할 수 있다.

선행 연구 결과에 따르면 $\mathrm{Ni} / \mathrm{Sn}-2.5 \mathrm{Ag} / \mathrm{Cu}$ 솔더 범프 구조 에 온도 $126.5{ }^{\circ} \mathrm{C}$, 전류밀도 $2.8 \times 10^{3} \mathrm{~A} / \mathrm{cm}^{2}$ 조건 하에서는 전자가 유입되는 음극 부분에서 금속 하부층과 솔더 계면에 서 보이드가 생성되어 진전과 동시에 금속 하부층이 소모가 일어난다고 보고되었다 [26]. 또한, $\mathrm{Ti} / \mathrm{Ni} / \mathrm{Cu} / \mathrm{Sn}-3 \mathrm{Ag}-1.5 \mathrm{Cu} /$ $\mathrm{Cu} / \mathrm{Ni} / \mathrm{Au}$ 솔더 범프 구조에 온도 $150{ }^{\circ} \mathrm{C}$, 전류밀도 $1 \times 10^{4}$ $\mathrm{A} / \mathrm{cm}^{2}$ 조건 하에서도 전자가 유입되는 부분에서 전류 집중 에 의해 보이드가 형성되고 그로 인해 국부적인 전류 집중에 의한 Joule heating 인해 원자 이동이 가속화되어 보이드가 성장하여 솔더와 금속간 화합물 계면을 따라 진전되어 결국 단락이 된다고 보고되었다 [27]. $\mathrm{Cu} / \mathrm{Ni} / \mathrm{Sn}-3.5 \mathrm{Ag} / \mathrm{Cu}$ 솔더 범 프 구조에서 온도 $150{ }^{\circ} \mathrm{C}$, 전류밀도 $7.9 \times 10^{3} \mathrm{~A} / \mathrm{cm}^{2}$ 조건 하 에서는 솔더와 금속간 화합물 사이 계면에서 보이드가 형성 되어 진전되었다고 보고하였다 [28]. 이처럼 전자가 유입되 는 음극 부분에서 전류 집중에 의해 솔더와 금속간 화합물 계 면에 보이드가 형성되어 진전되는 현상은 pancake-type 보이
드 손상기구이다.

한편, $\mathrm{Cu} / \mathrm{Sn}-3.0 \mathrm{Ag}-0.5 \mathrm{Cu} / \mathrm{Cu}$ 솔더 범프 구조에서 온도 $130{ }^{\circ} \mathrm{C}$ 에 전류밀도 $5.0 \times 10^{3} \mathrm{~A} / \mathrm{cm}^{2}$ 조건 하에서는 전자가 유 입되는 음극 부분에서 Joule heating과 전류 집중 현상의 영 향에 때문에 $\mathrm{Cu}$ pad의 $\mathrm{Cu}$ 원자가 완전히 소모되어 전기적 단 락이 일어난 것으로 보고하였다 [29]. $\mathrm{Cu} / \mathrm{Sn}-3.5 \mathrm{Ag} / \mathrm{Cu}$ 솔더 범프 구조에 온도 $140{ }^{\circ} \mathrm{C}$, 전류밀도 $7.9 \times 10^{3} \mathrm{~A} / \mathrm{cm}^{2}$ 조건 하 에서는 금속간 화합물과 솔더 계면에 보이드가 형성하여 전 파되어 솔더 범프의 파괴를 초래한다고 하였으며, 솔더 범프 파괴 시 보이드 계면 부근에서 단면적이 감소되어 극심한 전 류집중에 의해 Joule heating이 발생하여 높은 온도로 인해 보이드 부근에서 계면이 융해되는 현상이 관찰되었다고 보 고하였다 [30]. 전자가 유입되는 음극 부분에서 융해되는 현 상이 일어나는 것은 전류 집중 및 국부적인 Joule heating에 의한 손상기구이다.

이러한 무연 솔더 접합부의 $\mathrm{EM}$ 손상기구에 대한 선행 연 구 결과에 따르면 $\mathrm{Ni} / \mathrm{Sn}-2.5 \mathrm{Ag} / \mathrm{Cu}$ 솔더 범프 구조에 온도 $126.5{ }^{\circ} \mathrm{C}$, 전류밀도 $2.8 \times 10^{3} \mathrm{~A} / \mathrm{cm}^{2}$ 조건[26], Ti/ $/ \mathrm{Ni} / \mathrm{Cu} / \mathrm{Sn}$ $3 \mathrm{Ag}-1.5 \mathrm{Cu} / \mathrm{Cu} / \mathrm{Ni} / \mathrm{Au}$ 솔더 범프 구조에 온도 $150{ }^{\circ} \mathrm{C}$, 전류밀 도 $1 \times 10^{4} \mathrm{~A} / \mathrm{cm}^{2}$ 조건[27], $\mathrm{Cu} / \mathrm{Ni} / \mathrm{Sn}-3.5 \mathrm{Ag} / \mathrm{Cu}$ 솔더 범프 구 조에서 온도 $150{ }^{\circ} \mathrm{C}$, 전류밀도 $7.9 \times 10^{3} \mathrm{~A} / \mathrm{cm}^{2}$ 조건[28]과 같 이 다양한 구조 및 실험 조건에서 전자가 유입되는 음극 부분 에서 전류 집중에 의해 솔더와 금속간 화합물 계면에 보이드 가 형성되어 pancake 형상으로 보이드가 진전되어 전기적 단 락이 발생하는 pancake-type 보이드에 의한 손상기구로 널리 보고되었다.

한편, $\mathrm{Cu} / \mathrm{Sn}-3.0 \mathrm{Ag}-0.5 \mathrm{Cu} / \mathrm{Cu}$ 솔더 범프 구조에서 온도 $130{ }^{\circ} \mathrm{C}$ 에 전류밀도 $5.0 \times 10^{3} \mathrm{~A} / \mathrm{cm}^{2}$ 조건 [29]. $\mathrm{Cu} / \mathrm{Sn}-3.5 \mathrm{Ag} / \mathrm{Cu}$ 솔더 범프 구조에 온도 $140{ }^{\circ} \mathrm{C}$, 전류밀도 $7.9 \times 10^{3} \mathrm{~A} / \mathrm{cm}^{2}$ 조 건 [30] 과 같은 구조 및 실험 조건에서 전자가 유입되는 음극 모서리 부분에서 전류 집중에 의한 국부적인 Joule heating으 로 인해 UBM 또는 배선이 융해되어 전기적 단락이 발생하 는 손상기구로 널리 보고되었다.

$\mathrm{Ni}(\mathrm{V}) / \mathrm{Cu} / 99.3 \mathrm{Sn}-0.7 \mathrm{Cu} / \mathrm{Cu}$ 솔더 범프 구조에서 온도 150 ${ }^{\circ} \mathrm{C}$, 전류밀도 $3.7 \times 10^{4}, 6.4 \times 10^{4}, 7.4 \times 10^{4} \mathrm{~A} / \mathrm{cm}^{2}$ 세 가지 조 건 하에서는 높은 전류밀도와 낮은 전류밀도 상관없이 전자 가 유입되는 음극 부분에서 전류가 집중이 되어 솔더와 $\mathrm{Cu}$ $\mathrm{pad}$ 계면에서 보이드가 형성과 진전되어 전기적 단락이 일어 난다고 보고되었다 [31].

이와 같이 다양한 솔더 범프 구조 및 조성에서 $\mathrm{EM}$ 에 의한 손상기구에 대한 연구가 개별 조건 별로 많이 보고되어 왔으 


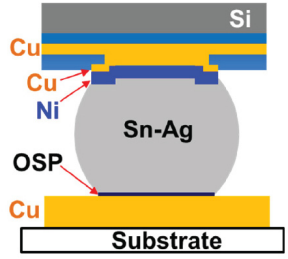

(a)

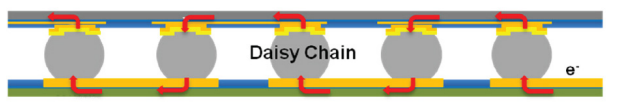

(b)

Fig. 1. Schematic structure of (a) $\mathrm{Cu} / \mathrm{Ni} / \mathrm{Sn}-\mathrm{Ag} / \mathrm{Cu}$ flip chip bump and (b) daisy chain for EM test

나, $\mathrm{Cu} / \mathrm{Ni} / \mathrm{Sn}-\mathrm{Ag} / \mathrm{Cu}$ 솔더 범프 구조에서 전류밀도 조건이 $\mathrm{EM}$ 손상기구에 미치는 영향에 대해 정밀하게 분석한 연구는 매우 미흡한 실정이다.

따라서, 본 연구에서는 $\mathrm{Cu} / \mathrm{Ni} / \mathrm{Sn}-\mathrm{Ag} / \mathrm{Cu}$ 솔더 범프 구조에 서 전류 밀도 조건에 따른 $\mathrm{EM}$ 손상기구를 전류 인가 시간에 따라 체계적으로 비교 분석하였다.

\section{2. 실험방법}

플립칩 $\mathrm{Cu} / \mathrm{Ni} / \mathrm{Sn}-\mathrm{Ag} / \mathrm{Cu}$ 솔더 범프에서 전류밀도에 따른 $\mathrm{EM}$ 손상기구를 분석하기 위하여 그림 1 과 같이 시편을 제작 하였다. 그림 1(a) 는 Sn-Ag 솔더 범프 시편의 단면 구조 모식 도이고, 전류인가 실험을 위해 그림 1(b)와 같이 daisy chain 구조로 제작하였다.

상부 칩 부분인 $\mathrm{Si}$ wafer에 씨앗층인 $\mathrm{TiW}$ 와 $\mathrm{Cu}$ 를 각각 0.1 $\mu \mathrm{m}, 0.2 \mu \mathrm{m}$ 두께로 스퍼터 증착한 후, $5 \mu \mathrm{m}$ 두께의 $\mathrm{Cu}$ 배선을 전기 도금으로 형성한 후, 스핀 코팅을 이용하여 $5 \mu \mathrm{m}$ 두께의 passivation층을 형성시켰다. 금속 하부층을 형성하기 위해 solder resist를 도포한 후 사진 식각 공정으로 패턴을 형성하 였고, $\mathrm{Cu}$ 배선 위에 $80 \mu \mathrm{m}$ 의 직경을 가지는 pad opening을 형성하였다. 형성 후, $\mathrm{Cu}$ 와 $\mathrm{Ni}$ 금속 하부층을 전기 도금을 이 용하여 각각 $5 \mu \mathrm{m}$ 와 $3 \mu \mathrm{m}$ 두께로 형성하였다. 마지막으로 전 기 도금으로 $\mathrm{Sn}-\mathrm{Ag}$ 솔더를 형성시켰다.

하부 기판 부분인 인쇄회로기판에는 $19 \mu \mathrm{m} \mathrm{Cu}$ 층을 전기 도금으로 형성한 후, $\mathrm{Cu}$ 산화를 방지하기 위해 OSP 표면처 리를 하였다. 제작 된 샘플은 rosin mind activity type(RMA) 플럭스를 도포한 후 플립칩 본더를 이용하여 정렬한 후, 150 ${ }^{\circ} \mathrm{C}$ 에서 3 초간 플럭스를 활성화 시킨 뒤 $250{ }^{\circ} \mathrm{C}$ 에서 1 분간 리 플로우 하여 플립칩 접합 시편을 제작하였다.

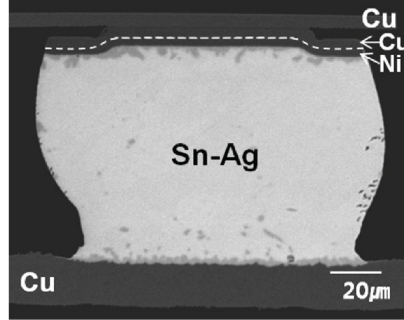

(a)

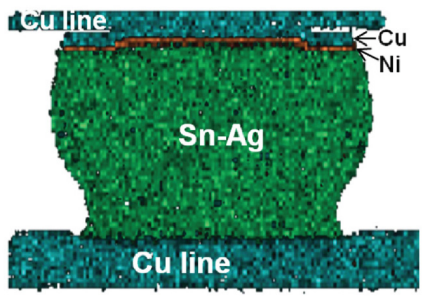

(b)

Fig. 2. Cross-sectional (a) SEM and (b) EDS mapping image of as-bonded $\mathrm{Cu} / \mathrm{Ni} / \mathrm{Sn}-\mathrm{Ag} / \mathrm{Cu}$ solder bump.

전류 밀도에 따른 손상기구를 분석하기에 앞서 먼저, 0 시 간의 $\mathrm{Cu} / \mathrm{Ni} / \mathrm{Sn}-\mathrm{Ag} / \mathrm{Cu}$ 시편의 구조를 분석하기 위해 단면 연 마 후 주사현미경(Scanning Electron Microscope, SEM)과 에 너지 분산형 X선 분광기(Energy Dispersive X - ray Spectroscopy, $\mathrm{EDS})$ 을 이용하여 분석을 진행하였으며, 그림 2에 나타내었 다. 그림 2(a)는 접합 직후의 $\mathrm{Cu} / \mathrm{Ni} / \mathrm{Sn}-\mathrm{Ag} / \mathrm{Cu}$ 솔더 범프의 SEM이미지이며, 그림 2(b)는 EDS mapping 분석을 통해 시 편의 구성 원소를 확인하였다. 전류밀도가 EM 손상기구에 미치는 영향을 확인하기 위해 아래와 같이 $\mathrm{EM}$ 실험 장치를 구성하였다. $150{ }^{\circ} \mathrm{C}$ 로 유지되는 열풍건조기(convection oven) 내부에서 $\mathrm{Cu} / \mathrm{Ni} / \mathrm{Sn}-\mathrm{Ag} / \mathrm{Cu}$ 시편에 열전대와 전극에 부 착시킨 후 Agilent 사의 E3648A power supply 장비를 이용하 여 전류를 인가하여 $\mathrm{EM}$ 실험을 실시하였다. 이 때 가해지는 전류는 솔더 pad opening 사이즈와 전류밀도 $5.0 \times 10^{3}, 6.9 \times$ $10^{3} \mathrm{~A} / \mathrm{cm}^{2}$ 조건을 계산하여 나온 값이다. EM 실험 시 실시간 저항 변화 측정은 Agilent 사의 37970A 장비를 이용하여 측 정하였으며, $\mathrm{EM}$ 전기적 단락 조건은 JEDEC-JEP 154 규격 [32] 조건에 따라 저항변화율이 $20 \%$ 이상일 때 전기적 단락 이 일어났다고 기준하였다. 전류밀도 $5.0 \times 10^{3} \mathrm{~A} / \mathrm{cm}^{2}$ 는 292 시간, 전류밀도 $6.9 \times 10^{3} \mathrm{~A} / \mathrm{cm}^{2}$ 는 25 시간에 전기적 단락이 발생하였으며, $\mathrm{SEM}$ 분석을 진행하여 $\mathrm{EM}$ 손상기구 분석하 였다. 


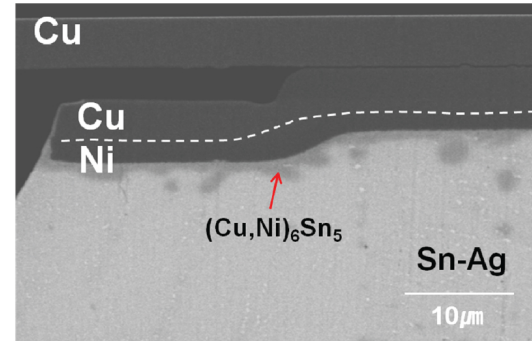

(a)

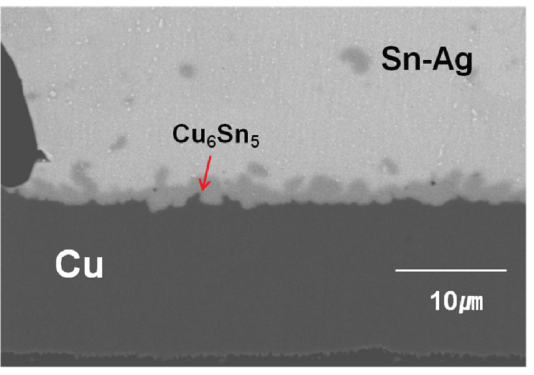

(b)

Fig. 3. Enlarged BSE images of solder bump bonding interface before EM testing: (a) upper interface and (b) lower interface.

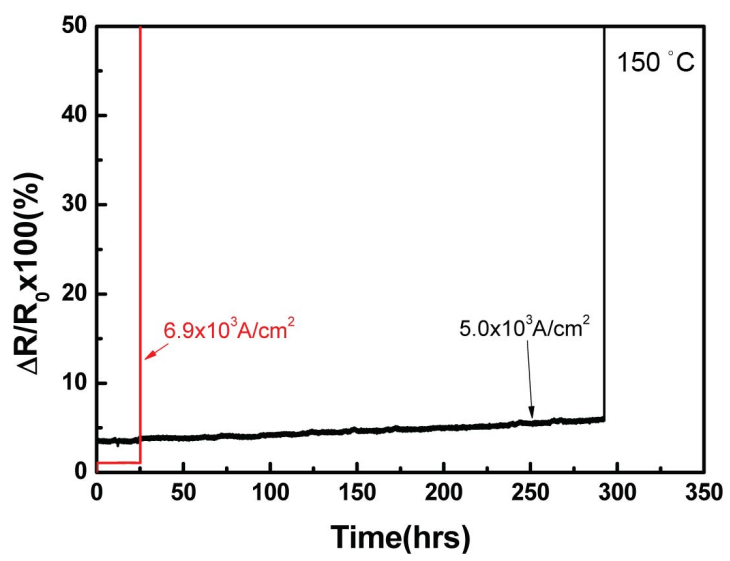

Fig. 4. Resistance change versus time curve of $\mathrm{Cu} / \mathrm{Ni} / \mathrm{Sn}-\mathrm{Ag} / \mathrm{Cu}$ bump for $5.0 \times 10^{3} \mathrm{~A} / \mathrm{cm}^{2}$ and $6.9 \times 10^{3} \mathrm{~A} / \mathrm{cm}^{2}$ at $150{ }^{\circ} \mathrm{C}$.

\section{3. 결과 및 고찰}

그림 3은 $\mathrm{Cu} / \mathrm{Ni} / \mathrm{Sn}-\mathrm{Ag} / \mathrm{Cu}$ 솔더 범프 접합 계면의 단면 $\mathrm{SEM}$ 미세구조를 나타내고 있다. EDS 분석 결과, 칩 부분인 그림 3(a)에서는 $\mathrm{Cu} / \mathrm{Ni}$ 금속 하부층과 $\mathrm{Sn}-\mathrm{Ag}$ 솔더 계면에서 $\mathrm{Cu} 33$ at $\%$, Ni 9 at $\%$, Sn 56 at $\%$ 의 $(\mathrm{Cu}, \mathrm{Ni})_{6} \mathrm{Sn}_{5}$ 상이 형성되었 고, 기판 부분인 그림 3(b)에는 $\mathrm{Cu}$ 배선과 $\mathrm{Sn}-\mathrm{Ag}$ 솔더 계면에 서 $\mathrm{Cu} 39 \mathrm{at} \%$ 와 $\mathrm{Sn} 56 \mathrm{at} \%$ 조성을 가지는 $\mathrm{Cu}_{6} \mathrm{Sn}_{5}$ 상이 형성 된 것을 확인 하였다. 그리고 솔더 내부에도 $\mathrm{Cu}_{6} \mathrm{Sn}_{5}$ 상이

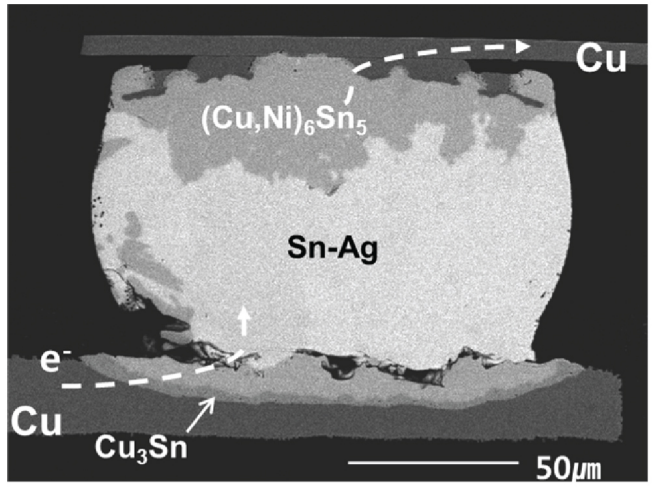

(a)

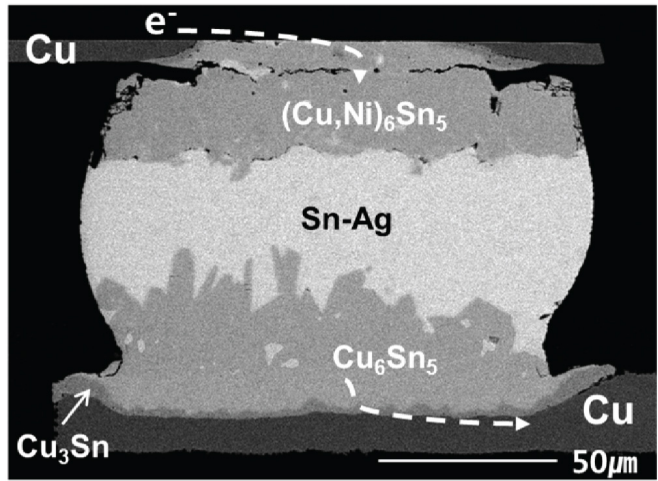

(b)

Fig, 5. EM failure images of $\mathrm{Cu} / \mathrm{Ni} / \mathrm{Sn}-\mathrm{Ag} / \mathrm{Cu}$ solder bump at 150 ${ }^{\circ} \mathrm{C}, 5.0 \times 10^{3} \mathrm{~A} / \mathrm{cm}^{2}$ : (a) an upward electron flow and (b) a downward electron flow.

spalling 되어 일부 형성되어 있는 것을 관찰하였다. $(\mathrm{Cu}, \mathrm{Ni})_{6} \mathrm{Sn}_{5}$ 상은 솔더 내의 $\mathrm{Sn}$ 과 금속 하부층인 $\mathrm{Cu}$ 와 $\mathrm{Ni}$ 이 리플로우 접합 시에 상호 확산 작용을 통해 생성된 것으로 판 단된다. 접합 후에 $\mathrm{Cu}_{6} \mathrm{Sn}_{5}$ 상이 먼저 형성되는 이유는 석출 구 동력이 큰 상일수록 먼저 석출되는데 $\mathrm{Cu}_{6} \mathrm{Sn}_{5}$ 상이 금속간 화 합물 중 표면 반응속도가 더 빠르다는 것을 보여주며 금속간 화합물 석출 구동력이 크다는 것을 알 수 있다 [33,34]. 석출 구동력이 큰 $\mathrm{Cu}_{6} \mathrm{Sn}_{5}$ 는 가리비 형상(scallop type)으로 좁고 둥 근 기둥 형태로 형성된 것을 알 수 있다. 이것은 금속간 화합 물 결정립의 곡률반경에 의한 용해도 차이가 발생하여 작은 결정립의 원자들이 큰 결정립으로 이동하는 깁슨-톰슨 (Gibbs-Thompson)효과로 설명된다 [33,35].

그림 4 는 $\mathrm{Cu} / \mathrm{Ni} / \mathrm{Sn}-\mathrm{Ag} / \mathrm{Cu}$ 솔더 범프에 온도 $150{ }^{\circ} \mathrm{C}$ 및 5.0 $\times 10^{3}, 6.9 \times 10^{3} \mathrm{~A} / \mathrm{cm}^{2}$ 두 가지 전류밀도에 대해 시간에 따른 실시간 저항 변화 그래프를 나타낸 그래프이다. 먼저 전류 밀 도 $5.0 \times 10^{3} \mathrm{~A} / \mathrm{cm}^{2}$ 조건에서는 저항이 서서히 증가하는 현상 을 보이다가 292시간에서 전기적 단락이 일어나 저항이 급격 
히 증가하였음을 알 수 있었다. 전류 밀도 $6.9 \times 10^{3} \mathrm{~A} / \mathrm{cm}^{2}$ 조 건에서는 전류밀도 $5.0 \times 10^{3} \mathrm{~A} / \mathrm{cm}^{2}$ 조건에 비해 저항이 서서 히 증가하는 구간은 보이지 않았으며, 25 시간에서 전기적 단 락이 일어나 저항이 급격히 증가하였음을 알 수 있었다.

그림 5 는 온도 $150{ }^{\circ} \mathrm{C}$, 전류밀도 $5.0 \times 10^{3} \mathrm{~A} / \mathrm{cm}^{2}$ 조건에서 $\mathrm{EM}$ 손상된 시편에 대한 전자 방향에 따른 미세구조를 보여 주고 있다. 먼저 그림 5(a)는 전자가 아래에서 위로 유입이 되 며, 그림 5(b)는 전자가 위에서 아래로 유입이 된다. 전자가 유입되는 음극 부분과 전자가 나가는 양극 부분의 금속간 화 합물의 두께가 다른 것을 확인하였다. 이러한 현상을 극성효 과(polarity effect)라고 하는데, 이는 주 확산종인 $\mathrm{Cu}$ 원자가 음극 배선에서 전자 이동에 따른 electron wind force 영향으 로 양극으로 빠르게 확산하여 $\mathrm{Sn}$ 과 반응하여 양극의 금속간 화합물 두께가 두꺼워지는 반면 전자가 유입되는 음극 부분 에는 $\mathrm{Cu}$ 원자가 빠져나가 금속간 화합물이 상대적으로 적게 성장되어 얇은 두께의 금속간 화합물이 형성된 것을 말한다 [36,37]. 그림 5(a), (b)에서 극성효과가 있음에도 불구하고 $\left(\mathrm{Cu}, \mathrm{Ni}_{6} \mathrm{Sn}_{5}\right.$ 의 두께가 비슷한 이유는 상-하부 $\mathrm{Cu}$ 배선의 단면 적 차이에 기인한 것으로 판단된다. 상부 $\mathrm{Cu}$ 배선의 두께는 5 $\mu \mathrm{m}$ 이며, 하부 $\mathrm{Cu}$ 배선의 두께는 $19 \mu \mathrm{m}$ 이므로, 상부 $\mathrm{Cu}$ 배선 이 하부 $\mathrm{Cu}$ 배선보다 상대적으로 높은 전류밀도가 가해진다. 따라서, 상부 $\mathrm{Cu}$ 배선에 하부보다 높은 Joule heating이 발생 하게 되고, 온도가 상대적으로 높은 상부 $\mathrm{Cu}$ 배선에서 상호 확산이 빠르기 때문에 polarity effect가 있음에도 불구하고 그림 $5(\mathrm{a})$ 의 음극과 그림 $5(\mathrm{~b})$ 의 양극에서 $\left(\mathrm{Cu}, \mathrm{Ni}_{6} \mathrm{Sn}_{5}\right.$ 의 두께 가 비슷하다고 판단된다.

그림 $5(\mathrm{a}),(\mathrm{b})$ 에서 상부 칩 부분에는 $(\mathrm{Cu}, \mathrm{Ni})_{6} \mathrm{Sn}_{5}$ 상이 성 장하였고, 하부 기판에는 $\mathrm{Cu}_{6} \mathrm{Sn}_{5}$ 과 $\mathrm{Cu}_{3} \mathrm{Sn}$ 상이 성장한 것을 관찰할 수 있었다. 이 때 $\mathrm{Cu}_{6} \mathrm{Sn}_{5}$ 상은 $\mathrm{Sn}$ 의 계면으로의 확산 장애물로 작용하여 총 확산 거리를 증가시켜 계면성장에 필 요한 $\mathrm{Sn}$ 의 공급을 지연시킴으로써 계면의 성장을 억제한다 고 알려져 있다 $[33,38,39] . \mathrm{Sn}$ 의 공급이 제한된 것과 달리 $\mathrm{Cu}$ 원자는 지속적으로 확산이 일어남으로써 $\mathrm{Cu} / \mathrm{Cu}_{6} \mathrm{Sn}_{5}$ 불평형 계면 사이에서 $\mathrm{Cu}_{3} \mathrm{Sn}$ 이 $\mathrm{Cu}_{6} \mathrm{Sn}_{5}$ 을 잠식하며 $\mathrm{Cu}$ 의 소모와 함 께 상전이가 일어난다고 보고하였다 [33]. 그림 5(a)는 전자 가 유입되는 하부 음극 부분에서 솔더/ $\mathrm{Cu}_{6} \mathrm{Sn}_{5}$ 계면에 접하는 솔더 내부에서 보이드가 형성되어 계면 따라 진전된 것을 관 찰하였으나, 그림 5(b)에 전자가 유입되는 상부 음극 부분의 솔더 $/ \mathrm{Cu}_{6} \mathrm{Sn}_{5}$ 계면에서는 보이드가 거의 관찰되지 않았고, 일 부 폴리싱에 의한 $\mathrm{Cu}_{6} \mathrm{Sn}_{5}$ 내부 균열이 관찰 되었다. 상부와 하부 계면에서 서로 다른 현상이 일어나는 이유는 상부에 $\mathrm{Ni}$

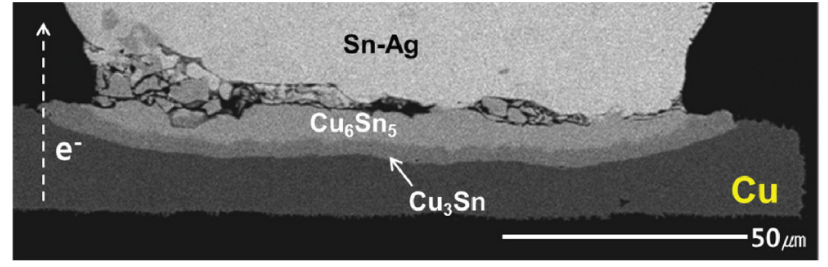

(a)

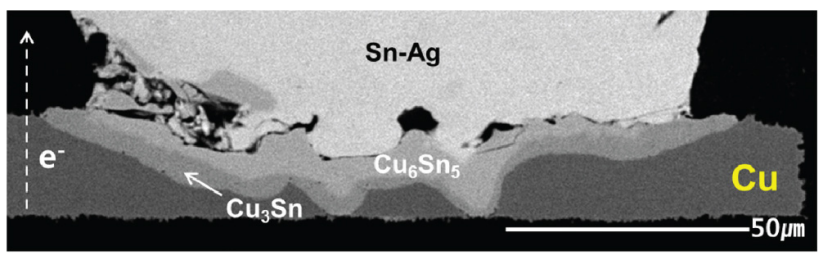

(b)

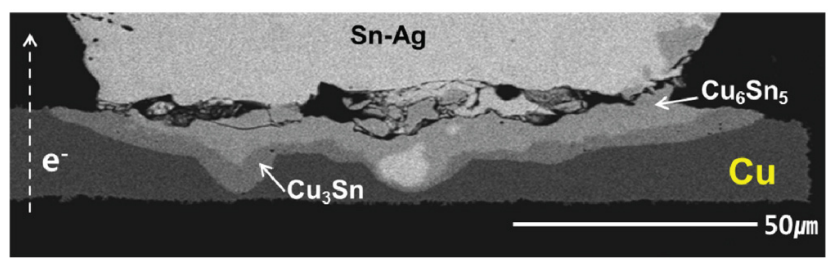

(c)

Fig. 6. Enlarged BSE images of bonding interface after EM failure at $150{ }^{\circ} \mathrm{C}, 5.0 \times 10^{3} \mathrm{~A} / \mathrm{cm}^{2}$ : (a) early stage of $\mathrm{Cu}$ depletion and void initiation, (b) pancake void propagation with resistance increase and (c) final open failure by complete pancake voiding.

층이 효과적인 $\mathrm{Cu}, \mathrm{Sn}$ 상호 확산 방지막 역할로 작용한 것으 로 판단된다. 또한 electron wind force에 의한 확산의 가속화 가 일어나 $\mathrm{Cu}$ 배선까지 $\mathrm{Sn}$ 이 반응하여 $\mathrm{Cu}_{6} \mathrm{Sn}_{5}, \mathrm{Cu}_{3} \mathrm{Sn}$ 상이 성장하였으며, 이러한 현상은 솔더 범프 뿐만 아니라 마이크 로 범프에서도 $\mathrm{EM}$ 시 발생하는 현상이다 [40-42].

그림 6은 전류밀도 $5.0 \times 10^{3} \mathrm{~A} / \mathrm{cm}^{2}$ 조건에서 전자가 유입 되는 음극인 하부 계면에서 보이드가 진전하는 손상기구를 명확히 이해하기 위해, 292시간에 전기적 단락이 발생한 시 편에서 서로 다른 범프의 하부 계면의 SEM 이미지를 손상 단계에 따라 나열하였다. 먼저 그림 6(a)에서 볼 수 있듯이 전 자가 유입되는 왼쪽 모서리의 $\mathrm{Sn}-\mathrm{Ag}$ 솔더/ $\mathrm{Cu}_{6} \mathrm{Sn}_{5}$ 경계부에서 flux divergence에 의해 $\mathrm{Cu}_{6} \mathrm{Sn}_{5}$ 와 접한 솔더 내부에 보이드가 형성되는 것을 관찰하였고, 그림 6(b) 와 같이 전자가 유입되 는 음극 모서리 부분에 형성된 보이드가 $\mathrm{Sn}-\mathrm{Ag}$ 솔더/ $/ \mathrm{Cu}_{6} \mathrm{Sn}_{5}$ 계면을 따라 점진적으로 진전되는 것을 관찰할 수 있다. 이는 $\mathrm{EM}$ 에 의해 하부 $\mathrm{Cu}$ 배선의 $\mathrm{Cu}$ 원자와 솔더가 반응에 의해 소모되어 보이드를 형성하였으며, 결국 그림 6(c)와 같이 전 기적 단락이 일어났음을 알 수 있었다. 이와 같이 보이드가 형성되고, 계면을 따라 진전되는 현상으로 인해 저항이 급격 


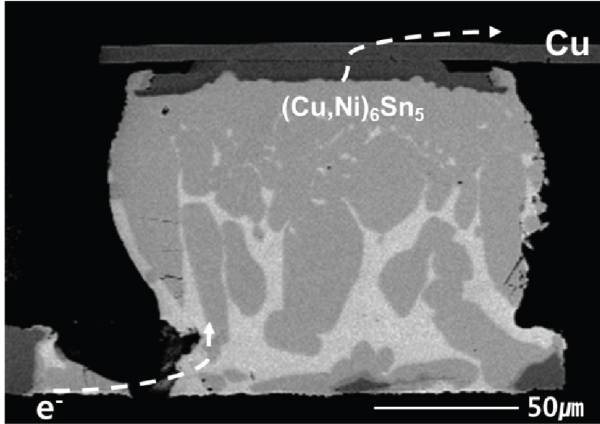

(a)

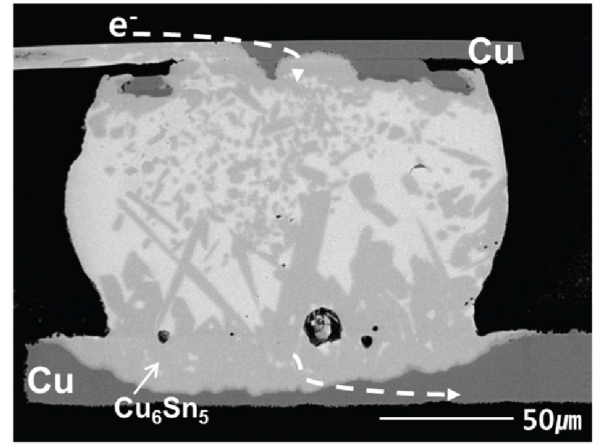

(b)

Fig. 7. EM failure images of $\mathrm{Cu} / \mathrm{Ni} / \mathrm{Sn}-\mathrm{Ag} / \mathrm{Cu}$ solder bump at 150 ${ }^{\circ} \mathrm{C}, 6.9 \times 10^{3} \mathrm{~A} / \mathrm{cm}^{2}$ : (a) an upward electron flow and (b) a downward electron flow.

히 증가한 것으로 판단되며, 낮은 전류밀도 조건에서 관찰되 는 금속간 화합물 계면에서 보이드가 형성한 후 진전되어 전 기적 단락이 일어나는 pancake type보이드가 형성되는 현상 [24,26-28]과 유사하게 관찰되었다. 이러한 현상은 선행 연구 에서 언급한 것과 같이 $\mathrm{Cu} / \mathrm{Ni} / \mathrm{Sn}-\mathrm{Ag} / \mathrm{Cu}$ 솔더 범프 뿐만 아니 라, $\mathrm{Ni} / \mathrm{Sn}-2.5 \mathrm{Ag} / \mathrm{Cu}, \quad \mathrm{Ti} / \mathrm{Ni} / \mathrm{Cu} / \mathrm{Sn}-3 \mathrm{Ag}-1.5 \mathrm{Cu} / \mathrm{Cu} / \mathrm{Ni} / \mathrm{Au}$, $\mathrm{Cu} / \mathrm{Ni} / \mathrm{Sn}-3.5 \mathrm{Ag} / \mathrm{Cu}, \mathrm{Ni}(\mathrm{V}) / \mathrm{Cu} / 99.3 \mathrm{Sn}-0.7 \mathrm{Cu} / \mathrm{Cu}$ 등 다양한 솔더 범프 구조에서 전류 인가 조건에 따라 발생하는 현상이 다 [26-28,31]. 또한, 손상 단계에 따라 높은 electron wind force에 의한 $\mathrm{Cu}$ 융해 및 $\mathrm{Sn}$ 의 상호확산으로 인해 $\mathrm{Cu}$ 배선에 $\mathrm{Cu}_{6} \mathrm{Sn}_{5}$ 와 $\mathrm{Cu}_{3} \mathrm{Sn}$ 상이 점차 크게 성장하는 것을 관찰하였다.

그림 7은 온도 $150{ }^{\circ} \mathrm{C}$, 전류밀도 $6.9 \times 10^{3} \mathrm{~A} / \mathrm{cm}^{2}$ 조건에서 $\mathrm{EM}$ 손상된 시편에 대한 전자 방향에 따른 미세구조를 보여 주고 있다. 먼저 그림 7(a)는 전자가 아래에서 위로 유입이 되 며, 그림 7(b)는 전자가 위에서 아래로 유입이 되는데, 전류밀 도 $5.0 \times 10^{3} \mathrm{~A} / \mathrm{cm}^{2}$ 조건과 유사하게 음극 부분과 양극 부분 에서 금속간 화합물이 서로 다른 두께를 가지는 극성효과가 나타나는 것이 관찰되었다. 반면, 전류밀도 $6.9 \times 10^{3} \mathrm{~A} / \mathrm{cm}^{2}$ 조건에서는 $\mathrm{Sn}-\mathrm{Ag}$ 솔더 범프 내부에 $\left(\mathrm{Cu}, \mathrm{Ni}_{6} \mathrm{Sn}_{5}\right.$ 상이 상당

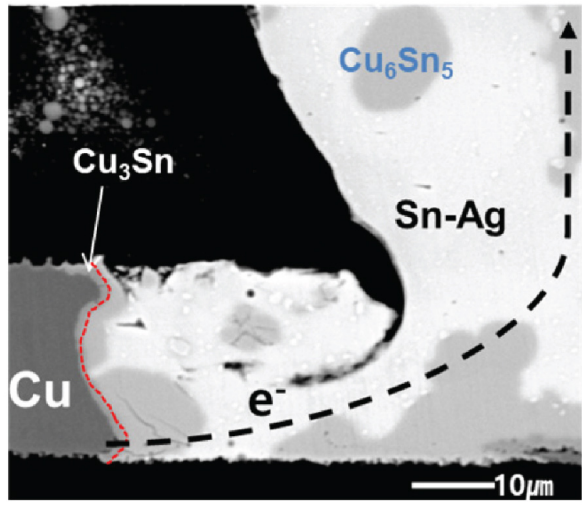

(a)

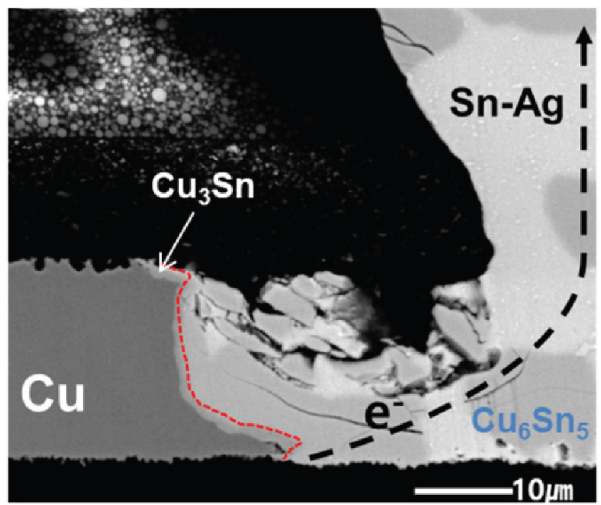

(b)

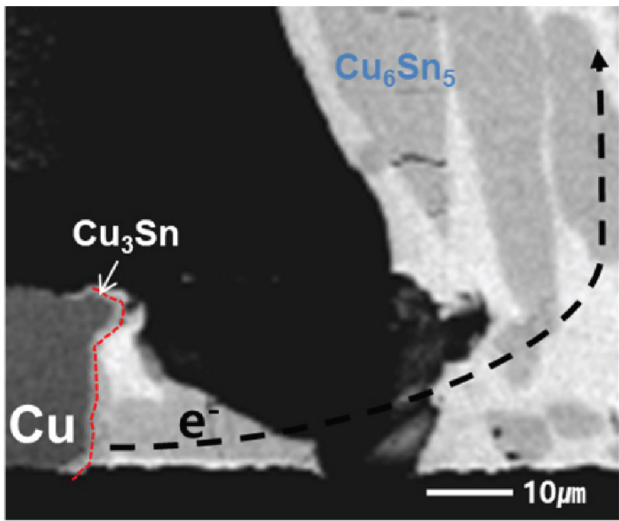

(c)

Fig. 8. Enlarged BSE images of lower corner bonding interface after EM failure at $150{ }^{\circ} \mathrm{C}, 6.9 \times 10^{3} \mathrm{~A} / \mathrm{cm}^{2}$ : (a) early stage of $\mathrm{Cu}$ depletion and accelerated IMC formation, (b) $\mathrm{Cu}$ line dissolution with resistance increase and (c) final $\mathrm{Cu}$ line open failure.

히 많이 형성되었는데, 이는 상대적으로 매우 높은 전류밀도 에 의한 electron wind force 효과로 인해 금속간 화합물의 성 장이 횔씬 가속화되었기 때문이라고 생각된다 [40]. 전류밀 도 $5.0 \times 10^{3} \mathrm{~A} / \mathrm{cm}^{2}$ 조건과 공통적으로 높은 electron wind force에 의한 $\mathrm{Cu}$ 융해 및 $\mathrm{Sn}$ 의 상호확산으로 인해 $\mathrm{Cu}_{6} \mathrm{Sn}_{5}$ 과 $\mathrm{Cu}_{3} \mathrm{Sn}$ 상이 $\mathrm{Cu}$ 배선 내부까지 성장되는 것을 관찰하였다. 그 
림 7(a)와 같이 전자가 유입되는 하부에서는 왼쪽 모서리 $\mathrm{Cu}$ 배선 내부에서 보이드가 매우 크게 성장하여 전기적 단락이 발생하였고, 그림 7(b)와 같이 전자가 유입되는 상부에서는 전기적 단락이 일어나지 않았음을 알 수 있었다. 이러한 이유 는 상부에는 $\mathrm{Cu}, \mathrm{Sn}$ 의 상호 확산에 대한 효과적인 확산 방지 막 역할을 하는 $\mathrm{Ni}$ 층이 존재하기 때문이라고 판단된다.

또한, 그림 7(a), (b)에서 공통적으로 $\mathrm{Cu}$ 배선으로 금속간 화합물이 성장하는 이유는 전자가 유입되는 음극에서 높은 electron wind force에 의한 $\mathrm{Cu}$ 융해 및 $\mathrm{Sn}$ 의 상호확산으로 인 해 $\mathrm{Cu}_{6} \mathrm{Sn}_{5}$ 과 $\mathrm{Cu}_{3} \mathrm{Sn}$ 상이 $\mathrm{Cu}$ 배선 내부까지 성장한 것으로 판 단된다.

그림 8 은 전류밀도 $6.9 \times 10^{3} \mathrm{~A} / \mathrm{cm}^{2}$ 조건에서 발생하는 손 상기구를 명확히 이해하기 위해, 25 시간에 전기적 단락이 발 생한 시편에서 서로 다른 범프의 전자가 유입되는 하부 음극 모서리 부분의 SEM 이미지를 확대하여 손상 단계에 따라 나 열하였다.

먼저 그림 8(a)는 높은 전류 인가 초기 단계이므로 전자가 들어가는 모서리 부분에서 전류 집중이 일어나 빠른 $\mathrm{Cu}$ 확산 으로 인한 급격한 $\mathrm{Cu}_{6} \mathrm{Sn}_{5}$ 상변화에 따른 $\mathrm{Cu}$ 배선 소모 현상 이 시작되는 단계이다. 그림 8(b)는 전류 집중에 의해 $\mathrm{Sn}-\mathrm{Ag}$ 솔더와 $\mathrm{Cu}_{6} \mathrm{Sn}_{5}$ 경계부에서 flux divergence에 의해 보이드가 커져 $\mathrm{Cu}$ 배선의 면적이 점점 작아져 전류밀도 집중 현상이 가속화되어 결국 그림 (c)와 같이 $\mathrm{Cu}$ 배선의 저항이 급격히 증가하여 전기적 단락이 일어났음을 알 수 있었다. 높은 전류 밀도 조건에서 관찰되는 전자가 유입되는 모서리 부분에서 솔더와 금속간 화합물 경계부에서 flux divergence에 의해 보 이드가 커져 전류가 집중되어 국부적인 Joule heating에 의해 $\mathrm{Cu}$ 배선에 $\mathrm{Cu}$ 원자 소모가 빠르게 일어나 전기적 단락이 일 어난 기존 문헌들과 유사한 손상거동임을 알 수 있다 $[25,29,30,43,44]$. 이러한 현상 K. Yamanaka에 의하면, 전자 가 유입되는 음극 모서리 부분이 $28 \times 10^{3} \mathrm{~A} / \mathrm{cm}^{2}$ 으로 솔더 보 다 3 배 높다고 하였으며, 전산모사를 통해 전자가 유입되는 음극 모서리 부분에 보이드가 형성되고, 성장할수록 전류 밀 도가 증가한다고 하였다 [45]. 또한 선행 연구에서 언급한 것 과 같이 $\mathrm{Cu} / \mathrm{Ni} / \mathrm{Sn}-\mathrm{Ag} / \mathrm{Cu}$ 솔더 범프 뿐만 아니라 $\mathrm{Cu} / \mathrm{Sn}-3.0 \mathrm{Ag}-0.5 \mathrm{Cu} / \mathrm{Cu}, \mathrm{Cu} / \mathrm{Sn}-3.5 \mathrm{Ag} / \mathrm{Cu}$ 등 다양한 솔더 범 프 구조에서 전류인가 조건 및 구조에 따라 발생하는 $\mathrm{EM}$ 손
상기구이다 [29,30]. 따라서, $\mathrm{Cu} / \mathrm{Ni} / \mathrm{Sn}-\mathrm{Ag} / \mathrm{Cu}$ 솔더 범프 구조 에서 전류밀도 조건 $5.0 \times 10^{3} \mathrm{~A} / \mathrm{cm}^{2}$ 에서는 낮은 전류밀도 조건에서 나타나는 현상인 전자가 유입되는 음극 모서리 부 분의 솔더/ $\mathrm{Cu}_{6} \mathrm{Sn}_{5}$ 금속간화합물 계면에서 보이드가 생성된 후 전체 계면을 따라 전파되어 나타나는 pancake type 보이드 손상기구가 지배하고, 전류밀도 $6.9 \times 10^{3} \mathrm{~A} / \mathrm{cm}^{2}$ 조건에서는 전자가 유입되는 음극 모서리 부분에 과도한 전류집중에 의 한 국부적인 Joule heating 지배 효과로 인한 손상기구가 지 배하는 것으로 판단된다. 따라서, 플립칩 $\mathrm{Sn}-\mathrm{Ag}$ 솔더 범프의 $\mathrm{EM}$ 손상기구는 $\mathrm{Ni}$ 확산방지층의 역할 및 전류밀도에 따른 전류집중 정도가 매우 중요한 인자 임을 알 수 있다.

\section{4. 결 론}

전류밀도에 따른 플립칩 $\mathrm{Cu} / \mathrm{Ni} / \mathrm{Sn}-\mathrm{Ag} / \mathrm{Cu}$ 솔더 범프의 $\mathrm{EM}$ 손상기구를 분석하였다. 전류밀도 $5.0 \times 10^{3} \mathrm{~A} / \mathrm{cm}^{2}$ 조건이 $6.9 \times 10^{3} \mathrm{~A} / \mathrm{cm}^{2}$ 보다 약 11 배 긴 $\mathrm{EM}$ 수명을 보였고, 낮은 전 류밀도 조건에서는 전자가 유입되는 음극 모서리 부분의 솔 더/ $\mathrm{Cu}_{6} \mathrm{Sn}_{5}$ 금속간화합물 계면의 solder 내부 pancake type 보 이드 형성 손상기구가 지배하고, 높은 전류밀도 조건에서는 전자가 유입되는 음극 모서리 부분에 과도한 전류집중에 의 한 국부적인 Joule heating 지배에 따른 손상기구가 지배함을 알 수 있었다. 따라서, 플립칩 Sn-Ag 솔더 범프의 $\mathrm{EM}$ 손상거 동은 솔더 접합부 $\mathrm{Ni}$ 확산방지층 유무 및 전자 유입부의 국부 적인 전류밀도 집중 정도가 지배 손상기구를 결정하는 매우 중요한 인자 임을 알 수 있다.

\section{감사의 글}

이 논문은 2017년도 정부(교육부)의 재원으로 한국연구재단 의 지원을 받아 수행된 기초연구사업(2016R1D1A3B03933937) 및 산업통상자원부(10067804)와 KSRC 지원 사업인 미래반 도체소자 원천기술개발사업의 연구결과로 수행되었으며, 시 편 제작에 도움을 주신 STS 반도체 통신 관계자 여러분께 감 사 드립니다. 


\section{REFERENCES}

1. J. W. Yoon, J. W. Kim, J. M. Koo, S. S. Ha, B. I. Noh, W. C. Moon, J. H. Moon, and S. B. Jung, J. of KWJS 25, 108 (2007).

2. K. N. Tu and K. Zeng, Master. Sci. Eng. 34, 1 (2001).

3. T. S. Oh, K. Y. Lee, Y. H. Lee, and B. Y. Jung, Met. Master. Int. 15, 479 (2009).

4. R. R. Tummala, Fundamentals of Microsystems packaging, McGraw-Hill Education, New York (2001).

5. Y. Liu, Microelectron. Reliab. 50, 514 (2010).

6. H. Shimaamoto, Proc. 56th Elec. Comp. C., USA (2007).

7. M. Y. Kim, T. S. Oh, and T. S. Oh, Korean. J. Met. Mater. 48, 557 (2010).

8. J. H. Lau, Low Cost Flip Chip Technologies for DCA, WLCSP, and PBGA Assemblies, pp.1-90, McGraw-Hill Professional, (2000).

9. J. Y. Choi, and T. S. Oh, J. Microelectron. Packag. Soc. 16, 9-15 (2009).

10. S. H. Kim, B. R. Lee, G. T. Park, J. M. Kim, S. H. Yoo, and Y. B. Park, Korean J. Met. Mater. 53, 735 (2015).

11. J. H. Ahn, K. S. Kim, Y. C. Lee, Y. I. Lim, and S. B. Jung, J. Microelectron. Packag. Soc. 17, 1 (2010).

12. Directive 2002/95/EC of the European Parliament and of the Council, Restriction of the Use of Certain Hazardous Substances in Electrical and Electronic Equipment (RoHS), EU (2003).

13. B. J. Lee, N. M. Hwang and H. M. Lee, Acta Mater. 45, 1867 (1997).

14. J. M. Kim, H. B. Lee, Y. S. Chang, and J. B. Choi, Met. Mater. Int. 19, 231 (2013).

15. V. Denis and C. Gilles, Proc. 18th Ieee/cpmt Int. El. Mfg., p. 101 (1995).

16. D. Chang, F. Bai, Y. P. Wang and C.S. Hsiao, Proc. 6th El. Packag. Tech. Conf., p. 149 (2004).

17. H. K. Lee, S. H. Son, H. Y. Lee, and J. M. Jeon, J. Kor. Inst. Surf. Eng. 40, 32 (2007).

18. M. H. Jeong, J. M. Kim, S. H. Yoo, C. W. Lee, and Y. B. Park, J. Microelectron. Packag. Soc. 17, 81 (2010).

19. K. N. Tu, J. W. Mayer, and L. C. Feldman, Electronic Thin Film Science for Electrical Engineering and Materials Scientists, pp.355-368, Macmillan, New York (1992).

20. K. N. Tu, J. Appl. Phys. 94, 5451 (2003).

21. T. Y. Lee, K. N. Tu, S. M. Kuo, and D. R. Frear, J. Appl. Phys. 89, 3189 (2001).

22. W. J. Choi, E. C. C. Yeh, and K. N. Tu, J. Appl. Phys. 89, 5665 (2003).

23. T. Y. Lee, K. N. Tu, and D. R. Frear, J. Appl. Phys. 90, 4502 (2001).
24. C. Chen, H. M. Tong, and K. N. Tu, Annu. Ann. Rev. Mater. Res., 41, 531-555 (2010).

25. C. E. Ho, C. R. Kao, and K. N. Tu, Advanced Filp Chip Packaging, Springer, New York (2013).

26. S. H. Chae, J. Im, T. Uehling, and P. S. Ho, 58th Elec. Comp. C., p.354-359, USA (2008).

27. M. H. R. Jen, L. C. Liu, and Y. S. Lai, Microelectron. Reliab. 49, 734 (2009).

28. H. Y. Chen, M. F. Ku, and C. Chen, Adv. Mater. Res-ger. 1, 83 (2012).

29. J. M. Kim, M. H. Jeong, S. H. Yoo, and Y. B. Park, J. Electron. Mater. 41, 791 (2012).

30. J. H. Lee, G. T. Lim, and Y. B. Park, J. Korean Phys. Soc. 54, 1784 (2009).

31. M. H. Chu, S. W. Liang, C. Chen, and A. T. Huang, J. Electron. Mater. 41, 2502 (2012).

32. Joint Electron Device Engineering Council, GUIDELINE FOR CHARACTERIZING SOLDER BUMP ELECTROMIGRATION UNDER CONSTANT CURRENT AND TEMPERATURE STRESS, USA (2008).

33. B. H. Kwak, M. H. Jeong, and Y. B. Park, Korean J. Met. Mater 50, 775 (2012).

34. K. N. Tu, Solder Joint Technology, Materials, Properties, and Reliability, pp.59-71, Springer, New York (2007).

35. D. A. Porter and K. E. Easterling, Phase Transformation in materials, 2nd ed, Chapman \& Hall, London (1992).

36. K. N. Tu, Solder Joint Technology, Materials, Properties, and Reliability. pp.289-303, Springer, New York (2007)

37. J. H. Lee, G. R. Lim, S. T. Yang, M. S. Suh, Q. H. Chung, K. Y. Byun, and Y. B. Park, Korean. J. Met. Mater. 46, 310 (2008).

38. M. H. Jeong, J. W. Kim, B. H. Kwak, B. J. Kim, K. W. Lee, J. D. Kim, Y. C. Joo, and Y. B. Park, Korean. J. Met. Mater. 49, 180 (2011).

39. S. Choi, T. R. Bieler, J. P. Lucas, and K. N. Subramanian, J. Electron. Mater. 28, 1209 (1999).

40. J. H. Lee, S. T. Yang, M. S. Suh, Q. H. Chung, K. Y. Byun, and Y. B. Park, Kor. J. Mater. Res. 17, 91 (2007).

41. J. Y. Kim, J. Yu, and S. H. Kim, Acta Mater. 57, 5001 (2009).

42. J. M. Park, S. H. Kim, M. H. Jeong, and Y. B. Park, J. Appl. Phys. 53, 05HA06 (2014).

43. T. Frank, C. Chappaz, P. Leduc, L. Arnaud, F. Lorut, S. Moreau, A. Thuaire, R. E. Farhane, and L. Anghel., Int. Rel. Phy., 3F.4.1-3F.4.6, USA (2011).

44. R Bauer, A. H. Fischer, C. Birzer, and L. Alexa, 61st Elec. Comp. C., 317-325, USA (2011).

45. K.Yamanaka, Y. Tsukada, and K.suganuma, Microelectron. Reliab. 47, 1280 (2007). 